\title{
PERAN INSTITUTIONAL REPOSITORY SEBAGAI MEDIA DISEMINASI LOCAL CONTENT PERGURUAN TINGGI
}

\author{
Sahidi \\ Program Studi Diploma 3 Perpustakaan \\ FKIP Universitas Tanjungpura \\ Email: sahidiip@fkip.untan.ac.id
}

\begin{abstract}
Abstrak
Tulisan ini mendeskripsikan peranan Institutional repository sebagai media diseminasi terhadap informasi local content bagi perguruan tinggi. Metode yang digunakan untuk menjawab dan mendeskripsikan masalah dalam tulisan ini menggunakan metode studi literatur. Penulis mengungkapkan peranan Institutional repository melalui kajian-kajian berdasarkan teori-teori yang relevan dengan tema yang diangkat oleh penulis. Institutional repository sebagai media menyimpanan, pelestarian, dan diseminasi informasi local content berbasis media teknologi akan bermanfaat jika didukung dengan kebijakan open access informasi. Manfaat yang dapat dirasakan dengan adanya Institutional repository melalui kebijakan open access informasi bagi penulis adalah sebagai sarana untuk menjukan terhadap karya ilmiah terbaiknya, sedangkan bagi institusinya mampu menaikan prestise serta visibilitas institusi di kancah nasional dan internasional. Riset yang berkualitas akan mampu menciptakan keunggulan dan mengharumkan nama baik universitas melalui repositori kelembagaan, meningkatkan minat untuk studi pada universitas tersebut, serta Institutional Repository dapat membangun collaborative research antara peneliti dari dalam negeri dan peneliti dari luar negeri.
\end{abstract}

Kata Kunci: Institutional repository, media diseminasi, local content

\begin{abstract}
This paper describes the role of the Institutional repository as a medium for disseminating local content information for universities. The method used to answer and describe the problem in this paper uses the literature study method. The author reveals the role of the Institutional repository through studies based on theories relevant to the theme raised by the author. Institutional repository as a medium for storing, preserving, and disseminating information on local content based on technology media will be useful if it is supported by an open access
\end{abstract}


information policy. The benefits that can be felt by the existence of an Institutional repository through an open access information policy for writers are as a means to show their best scientific work, while for the institution it is able to increase the prestige and visibility of the institution in the national and international arena. Quality research will be able to create excellence and make the university proud through institutional repositories, increase interest in studying at the university, and the Institutional Repository can build collaborative research between researchers from within the country and researchers from abroad.

Keywords: Institutional repository, media dissemination, local content 


\section{A. PENDAHULUAN}

Perguruan tinggi merupakan institusi dengan intensitas yang cukup tinggi dalam menghasilkan beragam hasil karya ilmiah dosen dan mahasiswa mulai dari laporan tugas akhir, skripsi, tesis, disertasi, hasil seminar, dan penelitian dosen, tentu semua itu memerlukan manajemen pengelolaan yang baik untuk mendukung pembelajaran. Pengelolaan yang dimaksud adalah menyimpan, dan mendiseminasikan karya-karya milik institusi, tentunya peran perkembangan teknologi informasi yang telah ada sangat mendukung dalam usaha pelestarian, menyimpan, dan mendiseminasikan local content perguruan tinggi.

Perkembangan dan tren yang digunakan oleh perguruan tinggi dalam usaha pelestarian, informasi local content terhadap karya institusi seperti yang telah diutarakan di atas adalah Institutional Repository atau media simpanan kelembagaan yang berbasis teknologi informasi. Institutional Repository disebut sebagai media penyimpanan hasil karya intelektual pada sebuah institusi seperti perguruan tinggi dengan maksud melestarikan, menyimpan, dan mendiseminasikan informasi local content dalam rangka meningkatkan akses informasi secara terbuka (open access) dan visibiltas bagi institusi.

Keberadaan repositori yang dimaksud digadang-gadang akan mampu memberikan kemudahan akses ke local content bagi para peneliti dalam mengakses informasi yang relevan dengan tipik-topil penelitian yang tarkait. Keberadaan institutional repository (IR) sebagai media baru yang diharapkan akan menyaring terhadap munculnya duplikasi penelitian ilmiah di kalangan akademisi dan keberadaan institutional repository (IR) juga diharapkan mampu menjadi media profesional sebagai pengelola ilmu pengetahuan berbasis teknologi informasi. 
Hal inilah yang melatar belakangi begi perguruan tinggi untuk menjadikan institutional repository (IR) sebagai tren media teknologi dalam knowledge management. Untuk menjadikan institutional repository (IR) sebagai tren media penyimpanan dan diseminasi informasi local content tentunya harus berupaya memanfaatkan teknologi informasi yang sudah berkembang saat ini. Menurut Fahrizandi (2020) implementasi teknologi informasi untuk perpustakaan dalam melayani pengguna bertujuan untuk membangun hak akses pengguna dalam menelusuri sumber digital, sumber rujukan elektronik melalui direktori elektronik, hasil penelitian dan informasi local content lainnya. Namun sangat disayangkan tidak semua institusi dengan jumlah informasi local content yang dihasilkan begitu banyak akan tetapi tidak dapat memanfaatkan teknologi informasi untuk membangun institutional repository (IR) sebagai tren knowledge management dan diseminasi informasi local content sehingga keberadaan local content hanya bertumpuk di meja-meja dosen dan tersusun rapi di perpustakaan.

Berdasarkan ulasan penulis di atas, terlihat bahwa keberadaan institutional repository (IR) sebagai media knowledge management, dan disemiinasi informasi local content bagi perguruan tinggi sangat penting dalam mengelola ilmu pengetahuan. Untuk itu, tulisan ini akan mengulas lebih jauh mengenai peran institutional repository (IR) sebagai wadah dalam mengelola, menyimpan, dan mendiseminasi local content perguruan tinggi.

\section{B. METODE PENELITIAN}

Penggunaan metode untuk mengupas permasalahan dalam tulisan ini menggunakan studi literatur dengan teknik analisis deskriptif terhadap isu permasalahan yang diangkat. Danial dan Warsiah (2009) memaknai bahwa Studi literatur yang dapat dilakukan oleh peneliti dengan cara mengumpulkan berbagai bahan 
bacaan seperti buku, artikel, dan majalah yang relevan dengan isu atau masalah yang dianggkat serta tujuan penelitian yang ingin dicapai. Teknik ini bertujuan untuk mengulas tema permasalahan dengan teori-teori yang relevan yang diungkap oleh penulis terkait peran institutional repository.

\section{PEMBahasan}

\section{Konsep Pengembangan Institutional Repository.}

Institutional repository secara konseptual dapat dimaknai sebagai media penyimpanan (archiving) yang dimiliki oleh lembaga pendidikan misalnya perguruan tinggi atau lembaga lainnya yang menghasilkan karya ilmiah. Menurut Lynch (2003), Institutional Repository sebagai rangkaian media (a set of services) pelayanan informasi dengan teknik manajemen informasi pemeliharaan, penyimpanan, serta diseminasi berbagai hasil pnelitian ilmiah yang dilakukan oleh masyarakat institusi dengan bentuk materimateri digital yang dikelola berbasis teknologi informasi. Menurut jones (2006) terdapat beberapa pengertian tentang Institutional Repository, yaitu:

a. Institutionaly defined ( media yang dimiliki oleh institusi dan memiliki tujuan)

b. Scholarly (hasil kegiatan bersifat ilmiah)

c. Cumulative and perpetual (melakukan pengumpulan dan pemeliharaan dengan tetap membuka diri terhadap ketersediaan informasi)

d. Open and Interproperable (Open Access and Open Archives Initiative complient)

e. Capturing and preserving events of campus life (mengumpulkan dan menyimpan informasi atau local content institusi)

f. Seacrble whithin constraints (mempermudah ditemukannya informasi local content). 
Berdasarkan definisi institutional repository penulis menyimpulkan bahwa institutional repository sebagai media yang dimiliki oleh institusi sebagai media komunikais ilmiah, sebagai media mengumpulkan dan melestarikan material local content dari perguruan tinggi agar tetap tersedia, ketersedian informasi local content yang bersifat open access bagi pengguna, dan memberikan kemudahan akses informasi local content bagi masyarakat.

\section{Tujuan Institutional Repository}

Menurut Pendit (2008) Institusional repository, sebenarnya memiliki kesamaan dalam menghimpun materi-materi digital. Namu Institusional repository sendiri difokuskan hanya mengelola materi-materi digital yang dihasilkan oleh masyarakat institusi itu sendiri (local content). Penggunaan repository sebagai konsep istilah yang digunakan dalam kegiatan penghimpunan dan pelestarian terhadap koleksi perpustakaan sesuai dengan nilai yang telah berakar di kalangan librarianship dan menjadi budaya manusia di perpustakaan hingga saat ini. Informasi local content sebagai koleksi intelektual dari komunitas tertentu menjadi material bagi repository institusi. Material dari informasi local content di perpustakaan memang telah mengalami perubahan, entah perubahan karena telah melalui proses digitasi atau memang terlahir sebaga digital (born digital). Namun, itu semua tidak akan pernah mampu mengubah nilai-nilai kepustakawanan yang telah berakar dan melekat pada implementasi institutional repository.

Abrizah (2009) menyatakan bahwa pembangunan sistem institutional repository memiliki tujuan utama yang sangat baik bagi keberadaan institusi.

a. Penyediaan link akses yang bersifat terbuka terhadap karya dosen, mahasiswa pada lembaga.

b. Sebagai bentuk penyediaan svisibilitas secara global dari seluruh hasil penelitian milik institusi. 
c. Sebagai media untuk menghimpun hasil karya milik institusi pada satu database online

d. Sebagai media penyimpnan (storage) terhadap seluruh asset digital baik yang tidak dipublikasikan secara bebas maupun yang dapat dipublikasikan yang dimiliki institusi.

Institutional repository sebagai strategi yang dapat diterapkan bagi universitas untuk menyesuaikan dengan kondisi masyarakat milenial saat ini dengan mengimplementasikan teknologi informasi sebagai basis pengelolaan data. Perpustakaan digital dan institutional repository sebagai ruang publik dapat dimungkinkan pendayagunaannya dari berbagai kalangan, sebagai anggota kampus maupun non anggota kampus (Tjiek, 2011). Untuk itu, pihak institusi perlu membangun dan mengembangkan layanan dengan infrastruktur yang mumpuni dan memiliki spesifikasi teknologi yang mampu menampung segala materi-materi lokal dengan penerapan institutional repository sesuai harapan.

Konsep infarastruktur dalam pengembangan institutional repository menurut Ware (2004), bahwa infrastruktur dalam membangun komunikasi ilmiah (scholarly communication) setidaknya harus memenuhi ketentuan dalam penerapannya;

a. Infrastruktur yang digunakan untuk mengumpulkan, menyimpan, dan diseminasi informasi local content terhadap ragam material karya ilmiah institusi adalah materi hasilhasil penelitian dan kontent yang berisi bidang keilmuan (scholarly material) dengan wadah database repository dengan sistem web online.

b. Insfrastruktur harus mampu menyimpan material informasi local content dengan jumlah besar karena dimungkinkan akan terus meningkat secara kuantitas dan dapat melakukan pelestarian dalam jangka panjang (long-term preservation) serta memberikan hak akses penuh (open access). 
c. Tingkat interoperability yang digunkan harus dapat dihandalkan dalam pelestarian jangka panjang dan dengan jumlah material yang cukup banyak dalam menggunakan OAI-compliant software.

Keberadaan Institutional repository dapat menjadi media publikasi berbasis web online dan terbuka bagi seluruh masyarakat institusi. Institutional repository yang mampu mempublis seluruh karya ilmiah institusi. Menurut Bankier dan Perciali (2008) Repository sebagai media utama bagi penulis untuk menampilkan karya yang dihasilkan serta profil akademiknya akan memberikan dampak atau visibilitas bagi institusi penulis. Strategi publikasi ke khalayak ramai terhadap seluruh karya merupakan wujud dari kegiatan memamerkan kekayaan intelektual lembaga agar bisa dimanfaatkan oleh masyaraka luas dengan prinsip (open access) dan dalam rangka pengembangan keilmuan secara berkelanjutan.

Open access informasi terhadap local content dalam rangka membangun komunikasi ilmiah yang berkelanjutan melalui pembangunan infrastruktur institutional repository diharapkan seluruh pengguna dapat memanfaatkan seluruh informasi dengan menerapkan budaya integritas yang tinggi dan penuh tanggung jawab. Jadi keberadaan institutional repository sebagai media diseminasi informasi local content yang terbuka tentu membutuhkan etika penggunaan secara bijak dan menghargai karya penulis.

3. Faktor Pendukung Penerapan Institutional Repository

Sedangkan menurut Westell dalam Pendit (2008) keberhasilan dalam pengembangan Institutional Repository akan dipengaruhi oleh beberapa faktor yaitu;

a. Adanya legitimasi dan mandat 
Untuk mencapai kesuksesan pengembangan pengembangan Institutional Repository diperlukan pengakuan dan dukungan yang formal dari pengelola tingkat atas. Hal ini merupakan faktor yang akan memberikan kontribusi yang berpengaruh signifikan terhadap program yang sedang dijalankan dalam rangka mencapai tujuan-tujuan yang telah dituju.

b. Penyatuan atau mengintegrasikan dengan rencana institusi Pelru penetapan arah kebijakan yang jelas untuk membangun kesinambungan program yang berjalan. Untuk itu, perlu perencanaan yang berjangka secara priodik dalam rangka menstabilkan partisipasi sumber daya manusia yang terlibat dalam program.

c. Suntikan Dana (Capital)

Awalnya, sebagian besar deposito institusional didanai oleh individu dan sumber sporadis. Seiring waktu, keinginan dan persepsi untuk memasukkan mereka ke dalam anggaran resmi. Beberapa institusi dan universitas mulai membebankan biaya untuk menutupi biaya pembelian koleksi dan pemeliharaan sistem.

d. Digitalisasi dalam Repository

Untuk mengumpulkan dokumen-dokumen yang ada dalam bentuk kertas, perpustakaan akademik memainkan peran pentingnya dalam melakukan transisi dari dokumen kertas ke dokumen digital. Kegiatan Digitalisasi koleksi akan mempercepat proses penyimpanan dan juga dapat menentukan keberlangsungan repository lembaga. Jadi digitalisasi menjadi isu penting dalam memainkan perannya dalam pengembangan program repository institusi.

e. Interoprabilitas

Fenomena open access menjadikan faktor bahwa pengembangan repository kelembagaan harus membuat kebijakan yang jelas terkait keterbukaan metadata dan 145 
kapasitas pertukaran antar lintas sistem berupa federated search dan pemanenan data (harvesting)

f. Evaluasi dan pengukuran

Kuantitas jumlah koleksi atau dokumen yang dikirim merupakan salah satu tantangan dalam pengembangan institutional repository, karena tingkat partisipasi pengirim dokumen dapat diukur dan dievaluasi sejauhmana tingkat pendaygunaan koleksi tersebut. Untuk itu, pengelolaan dan pengembangan institutional repository harus membuat alat ukur yang mampu mendeteksi pendayagunaan dari sisi jumlah pengguna, koleksi yang digunakan, dan jumlah koleksi yang dikutip oleh pengguna sebagai bahan rujukan.

g. Promosi IR

Hasil pengukuran dan evaluasi terhadap pengelolaan dan pengembangan institutional repository dapat menjadi bahan promosi untuk meningkatkan keterlibata seluruh warga akademik dalam kegiatan literasi digital dan literasi informasi.

h. Starategi prservasi digital

Preservasi digital merupakan isu utama yang tidak boleh dilupakan dalam pengelolaan pengembangan institutional repository. Pengelolaan dan pengembangan institutional repository merupakan sistem yang saling terbangun untuk mencapai kesuksesan. Untuk itu, perlu adanya pengawasan terhada sistem yang digunakan dan harus ada perbaikan terhadap sistem jika mengalami kendala, agar sistem pengelolaan dan pengembangan institutional repository tetap berjalan dan informasi yang dikandung tetap terlindungi untuk jangka waktu yang panjang.

4. Peran Institutional Repository dalam Diseminasi Informasi Local Content 
Pengembangan Institutional Repository bagi lembaga perguruan tinggi akan memberikan dampak yang siknifikan terhadap penulis dan lembaga. Manfaat yang dapat diarasakan oleh penulis adalah sebagai sarana untuk menjukan terhadap karya ilmiah terbaiknya, mampu menaikan prestise bagi institusi serta visibilitas institusi sendiri. Hasil riset yang berkualitas akan mampu menciptakan keunggulan dan mengahrumkan nama universitas melalui repositori kelembagaan, dapat mengenalkan universitas dimata calon mahasiswa dan meningkatkan minat untuk studi pada universitas tersebut, serta Institutional Repository dapat membangun collaborative research antara peneliti di dalam dan dari luar negeri. (Harliansyah, 2016)

Keberadaan Institutional Repository memang sangat memberikan manfaat bagi institusi untuk memamerkan local content yang dimilikinya agar dapat dibaca dan dimanfaatkan secara berkelanjutan yang tidak hanya dari anggota universitas sendiri akan tetapi dapat dimanfaatkan secara terbuka kepada pihak siapa saja yang membutuhkannya. Institutional Repository bukan hanya memberikan manfaat bagi pemenuhan kebutuhan informasi bagi seluruh pengguna, akan tetapi manfaatnya akan kembali pada diri institusi sebagai lembaga yang memiliki banyak karya yang dihasilkan berupa peningkatan citra dan nama institusi.

Repository memiliki kemampuan dalam peningkatan visibilitas institusi melalui karya ilmiah dan hasil penelitian dosen dan mahasiswa. Melalui kemampuan ini, hasil penelitian dan seluruh karya dapat diakses secara mudah melalui mesin pencarian karya ilmiah (academic search engine) berupa search engine Base, Core, dan Google Scholar serta search engine lainnya. Menurut hasil studi keberadaan Beberapa riset mengungkapkan bahwa keberadaan repository pada institusi memiliki kemampuan atau berpotensi besar dalam mengembangkan visibitas secara global 
(Repanovici, 2001). Sedangkan kontribusi repository institusi bagi penulis (dosen, peneliti, penulis) sebagai media dalam memanajemen kegiatan-kegiatan riset dalam meningkatkan jenjang karir dosen, peneliti, dan penulis kearah yang lebih baik kedepannya. Untuk itu, perlu adanya sistem pembagunan institutional repository secara open access informasi terhadap local content milik perguruan tinggi.

Latar belakang lahirnya konsep open access informasi menjadi model dalam membangun komunikasi ilmiah sebagai strategi dalam meningkatkan hak akses terhadap hasil penelitianpenelitian atau local content informasi institusi. Kontribusi konsep open access informasi akan membangun lingkungan teknologi global secara efektif dan efisien melalui budaya sharing ilmu pengetahuan dan akses terbuka terhadap karya milik institusi (Fatmawati, 2013).

Abrizah (2009) menyatakan bahwa manfaat yang ada dengan Institutional Repository adalah sebagai berikut:

a. Institutional Repository dapat membuka aset yang dimiliki lembaga kepada dunia

b. Institutional Repository dapat meningkatkan visibilitas lembaga sebagai akibat kontribusinya terhadap pemenuhan kebutuhan informasi masyarakat pengguna.

c. Institutional Repository dapat memenajemen ilmu pengethuan yang berbentuk digital (explicit knowledge) sehingga dapat dilestraikan dalam jangka waktu lama dan didiseminasikan kepada masyarakat.

d. Institutional Repository dapat mendistribusikan informasi local content berupa hasil penelitian dan pengajaran dalam rangka membangun komunikasi keilmuan..

e. Sebagai media Penyediaan ruangan untuk berkerativitas dalam menyelesaikan proyek dengan sistem kolaboratif. 
f. Sebagai media pendorong untuk peningkatakan penelitian dengan interdsciplinar keilmuan.

g. Sebagai fasilitas bahan untuk pengajaran dan membagi materimateri digital.

h. Memberikan akses terbuka untuk pengembangan e-potofolio ke dalam materi-materi digital tesis dan materi digital disertasi serta hasil penelitian lainnya.

Institutional repository memang menjadi alternatif media teknologi knowledge management yang intensitasnya penggunaanya cukup tinggi, karena memang media ini dapat didukung dengan kebijakan secara terbuka agar informasi local content berupa materi digital yang tersimpan di dalam institutional repository dapat dimanfaatkan secara maksimal oleh masyarakat akademik. Bailey (2015) merinci dari keuntungan institutional repository diharapkan dapat menerapkan sistem open access informasi : 1) Sebagai media yang mampu menghimpun dan menyediakan informasi local content dengan sistem terpadu dan membangun interaksi antar sistem, agar dapat memudahkan akses dan keberadaan pengetahuan juga dapat saling ditransfer satu sama lain, 2) membangun sistem yang terbuka terhadap karya ilmiah sebagai upaya atau strategi dalam melihat dan meningkatkan jumlah sitasi terhadap karya dan selanjutnya akan berdampak pada reputasi institusi. 


\section{PENUTUP}

Institutional Repository merupakan media penyimpanan karyakarya intelektual berupa informasi local content di perguruan tinggi dalam kegiatan knowledge management. Knowledge management melalui media institutional repository terhadap kekayaan institusi perlu didukung dengan kebijakan open access informasi, sehingga keberadaan informasi local content pada Institutional Repository dapat memberikan kontribusi besar dalam mendiseminasikan informasi local content dan dapat meningkatkan ketersediaan informasi bagi penggunannya dari waktu ke waktu sebagai usaha membangun komunikasi ilmiah 


\section{DAFTAR PUSTAKA}

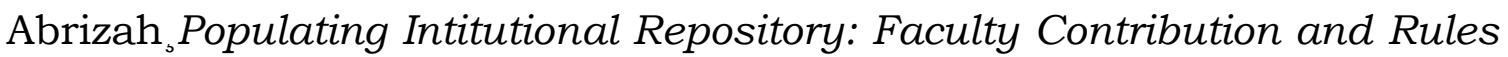
of Librarian,Paper Presented at the international seminar and workshop on open source system and web 2.0 technology in libraries. Semarang10-11 Agustus 2009, organized by faculty of culture Diponegoro University.

Bankier, Jean-Gabriel and Perciali, Irene. 2008. "The Institutional Repository Rediscovered: What Can a University Do for Open Access Publishing?”, dalam Serials Review, 34(1),(March, 2008), 22.(http://linkinghub.elsevier.com/retrieve/pii diunduh 26 Desember 2016.

Bailey Jr., Charles W. Open Access and Libraries. Diunduh dari http://www.digitalscholarship.org/cwb/OALibraries2.pdf. $\underline{26 / 12 / 2015}$.

Danial, Endang \& Nanan, Warsiah. (2009). Metode Penulisan Karya Ilmiah. Bandung: Laboratorium Pendidikan Kewarganegaraan.

Fahrizandi. 2020. Pemanfaatan Teknologi Informasi di Perpustakaan. Jurnal Ilmu Perpustakaan dan Informasi. 4 (1): 63-68. DOI: http://dx.doi.org/10.29240/tik.v4i1.1160

Fatmawati, Endang. 2013. Gerakan Open Acces dalam Mendukung Komunikasi Keilmuan.Jurnal Visi Pustaka Vol. 15, No. 2, Agustus.2013.

Harliansyah, Faizuddin.2016. Institutional Repository Sebagai Sarana Komunikasi Ilmiah Yang Sustainable dan Reliable.Pustakaloka Jurnal Kajian Informasi dan Perpustakaan, 8 (1): 1-2. DOI: $\underline{10.21154 / \text { pustakaloka.v8i1.497 }}$

Jones.R, Andrew, T. and MacColl, J.2006. The Institutinal Repository.Oxford: Chandos.

Lynch, Clifford A.2003. "Institutional Repositories: Essential Infrastructure for Scholarship in the Digital Age," Portal: Libraries and the Academy 3, no. 2.

Pendit, Putu Laksman.2008.Perpustakaan Digital dari A-Z,Jakarta: Cipta Karsa.

Repanovici, Angel. "Measuring the Visibility of the University"s Scientific Production through Scientometric Methods: An Exploratory Study at the Transilvania University of Brasov, Romania," Performance Measurement and Metrics 12, no. 2 (July 5, 2011).

Tjiek, Liauw Tong. 2011. Institutional Repositories : Facilitating structure, collaborations, scholarlycommunications, and institutional 
visibility, dalam Book ChapterBook Chapter in "DigitalLibraries : Methods and Applications" - Editor: Kuo Hung Huang . Croatia :In Tech.

Ware, Mark. 2004. Pathfinder Research on Web-Based Repositories.London: Publisher and Library/Learning Solutions. 